\title{
FLEXIBLE WELLBEING AND ORGANIZATIONAL CREATIVITY: PERSONALITY TRAITS ROLE
}

\author{
Jones UMUKORO@1 ${ }^{1}$, Johnson EGWAKHE (D)2, Victoria AKPA (D3 \\ ${ }^{1,3}$ Department of Business Administration and Marketing, Babcock University, Ilishan-Remo Ogun State, Nigeria \\ ${ }^{2}$ School of Management Sciences, Babcock University, Ilishan-Remo Ogun State, Nigeria
}

Received 25 March 2020; accepted 24 June 2021

\begin{abstract}
Organizational creativity is indispensable in a highly competitive and dynamic academic environment; and the role of individuals is mostly unquantifiable. Hence the study argued that the ideas, novel research output, patents, grants of the academic staff depend on the flexible wellbeing of the workforce which is at a low level in Nigeria. Thus, the paper investigated the role of personality traits on the relationship between flexible wellbeing and organizational creativity. The paper implemented a cross-sectional survey research design and collated data from six hundred and twenty-one academic staff ranked from Senior Lecturer to Professor from eight selected private universities in South-West, Nigeria through applying multi-stage random sampling technique. Reliable and validated tests were conducted on the adapted questionnaire before it was used for the study. The result from hierarchical regression analysis using SPSS add-on called process analysis revealed that personality traits have a moderating effect on the interactions between flexible wellbeing and organizational creativity $\left(\Delta R^{2}=0.014, \Delta F(1,528)=13.579, p<0.05\right)$. Management to tailor wellbeing policies and practices to workers' creative drive as there is no "one-size-fits-all" approach to designing an effective flexible wellbeing strategy.
\end{abstract}

Keywords: flexible wellbeing, organizational creativity, personality traits.

JEL Classification: M1, M12, D3.

\section{Introduction}

Organizational creativity intellectually has been referred to interchangeably as individual creativity and team creativity. A concept in which to innovate and create is the benchmark for assessing individuals and organizations' performance and output (Amabile \& Pratt, 2016; Gupta \& Banerjee, 2016; Sadi, 2019). However, Nigeria has maintained rankings in the lower regions on organizational creativity.

For instance, a 2015 report from 139 countries on the Global Creativity Index showed that organizations in countries such as the United States, Canada, Australia, and New Zealand ranked within the top ten on the level of investment in research and development and patents per-capita; while South Africa, Kenya, and Cameroon are the African countries ranked between 39 and 72 positions. However, because of inaccessibility to essential creativity data Nigeria was not ranked (Cornell University, European Institute of Business Administration [INSEAD] \& World Intellectual Property Organization [WIPO], 2015; Dimnwobi et al., 2016).
More so, in 2018 and 2019, Nigeria ranked 131 of 140 countries and 135 of 141 countries respectively for critical thinking in teaching and research skills (World Economic Forum, 2018, 2019) thereby, continuing creativity rankings in the lower regions. These lower creativity rankings have remained a growing concern in the Nigerian education market thus, resulting in a weak brand image.

The Organization for Economic Cooperation and Development [OECD] (2018) report indicated that creativity is among the most significant abilities needed in the future for organizations to be competitive, hence both individuals and teams are required to solve issues and adapt in increasingly complex places of work and environments. Likewise, most concepts for attaining business growth, profile rankings, and recognition are achieved through people (Abubakar et al., 2018). Nevertheless, while organizational creativity is vital to achieve and maintain top rankings, wellbeing measures, in terms of both financial and non-financial investments to support creativity (Sadi, 2019), could comprise factors in the drive for creativity. Consequently, in the opinion of Corazza (2016) and Umukoro et al. (2021), to achieve creativity, there could be the

*Corresponding author. E-mail: umukoroj@babcock.edu.ng 
need to consider organizational creativity in line with flexible wellbeing measures.

Relating to wellbeing, scholars have stressed that the most common word revolving around how well individuals are doing includes material, health, mental, social, environmental, and subjective dimensions of wellbeing (Diener et al., 2018; Lovell \& Beckstrand, 2015). Therefore, a report by the Chartered Institute of Personnel Development [CIPD] (2019) stressed that a single measure of wellbeing intervention might improve some aspects of wellbeing for creativity but not all. Therefore, understanding and critically conceptualizing the design of policies for enhancing workers' wellbeing to be all-encompassing is momentous.

Wellbeing in the education sector has not fared well, as researchers acquiesced that in the past few decades, the demand on academics has not been commensurate with wellbeing measures made available in the workplaces (Mudrak et al., 2017; Omole, 2018). Rather the wellbeing of academic staff members has maintained a steady decline (Kinman \& Wray, 2019; Odigiri et al., 2020; Shin \& Jung, 2014).

Accordingly, literature and reports have shown that flexible wellbeing enhances work productivity, improves skills, and higher job satisfaction (Nangoy et al., 2020; Ishola, 2017). Also, in varied sectors, wellbeing is a panacea for the holistic enhancement of mental and physical health and creativity. However, commentaries have it that the absence of flexible wellbeing could result in disengagement, isolation and alienation, low achievement, decline in competitive advantage, and ultimately sudden death of workers (Lovell \& Beckstrand, 2015; Omole, 2018; World Health Organization, 2014). But the puzzling question is what role does personality traits play in workers' creativity alongside the link with flexible wellbeing measures made available?

In light of these submissions, the position of Abdullah et al. (2016) is that since individuals are an embodiment of either similar and or dissimilar characteristics, the level at which the individual, the environment, and personality traits interact could be crucial to creativity. Abdullah et al. (2016) submission was earlier emphasized by Dul and Ceylan (2011) that individuals desire some environment to others based on their personality differences. Based on these submissions, research interest on the role of personality traits elements with academic achievement is increasing (Alghamdi et al., 2017; Eyong et al., 2014; Umukoro \& Egwakhe, 2019).

Results from studies conducted on personality traits, flexible wellbeing, and organizational creativity have been inconclusive over the past decades. For instance, Ali (2018) found that extraversion, agreeableness, conscientiousness, and openness to experience had a positive influence on individual innovativeness, creativity, and satisfaction with life perceptions but, neuroticism was negatively related. Likewise, other researchers (Gorondutse \& John, 2018; Robert et al., 2020; Zhou \& Shalley, 2018) found that individual characteristics, work environment, wellbeing measures, and other hypothetically pertinent contextual factors either augment or limit creativity depending on applicability, modification, and acceptability.

Further, other scholars' commented that the concept of personality traits in creativity is more intricate than initially perceived (Abdullah et al., 2016; Chau et al., 2018; Chen et al., 2017). Nevertheless, these previous studies were conducted in Western countries and seldom in the Education industry and Nigeria. In light of these gaps, this paper focused on the research objective and hypothesis thus stated.

\section{Research objective:}

Determine whether the effect of personality traits moderated the relationship between flexible wellbeing and organizational creativity.

\section{Research hypothesis:}

Personality traits have no significant moderating effect on the relationship between flexible wellbeing and organizational creativity.

\section{Literature review}

\subsection{Organizational creativity}

Conceptually, Derecskei (2015) referred to organizational creativity as the extension of creativity concept within an organizational framework. Other scholars defined the concept as production of valuable, novel, useful, or appropriate concepts (Amabile \& Pratt, 2016; Blomberg et al., 2017), products, processes, or services (Corazza, 2016; Jain \& Jain, 2017) taking place in the context of an organization and individuals working either independently or together in a multifaceted social system. For this work, the researchers defined organizational creativity as, ideas, novel research output, patents, grants, and recognition, resulting from the integration of the person(s) who creates, the process provided, and the resources and environment made available in the workplace.

\subsection{Flexible wellbeing}

Previous definitions of flexible wellbeing have either focused on wellness, resources, and or mental; physical health; financial, and social health. Taylor (2015) narrowed wellbeing to the resources available to workers, operational systems in the organization, how work is executed, and work experience. In the opinion of Lovell and Beckstrand (2015), the sensitivity of the progression in a person's life, both in the present and possibly in the future determines wellbeing. Consequently, the researchers defined flexible wellbeing as, a dynamic and continuous adaptation of wellbeing measures made available for workers to respond to the changing environment in order to match the individual's job demands to achieve both individual and organizational goals.

\subsection{Personality traits}

The concept of personality refers to unique characteristics deposited in each individual that enables the evaluation 
of a person's behavior and or uniqueness (Cervone \& Vittorio, 2000). Hence Eyong et al. (2014) defined a trait as a property within the individual that accounts for the individual's unique but relatively stable reactions to the environment. In the opinion of Ndubuisi-Okolo et al. (2017) and Osita-Ejikeme and Worlu (2017), these personality and traits are developed in an individual based on several whole psychological systems including numerous factors accruing from the workplaces.

Interestingly, the Big Five personality factors are applied in categorizing each individual (Rothmann \& Coetzer, 2003). While openness to experience refers to a person who shows appreciation for adventure, curiosity, novelty, sensitivity, independent-minded, and intellect; a conscientious individual has the tendency to demonstrate self-discipline with the goal for accomplishment. dependable, punctual, organized and systematic, conformity, diligent, vigilant, attentive, cautious, logical, comprehensive, determined, eat better and exercise more and avoid risky behaviors (Abdullah et al., 2016; Yazdi \& Mustamil, 2015).

Conversely, individuals possessing social energy, ability to tolerate sensory stimulation from both people and situations refer to extraversion (Ali, 2018). On the other hand, individuals with the ability to trust, tolerant, nice, sensitive, kind, and having the tendency to be compassionate depicts agreeableness individuals (Osita-Ejikeme \& Worlu, 2017). Individuals with the tendency to easily experience negative feelings such as anger, anxiety, or depression and are emotionally insecure and uneven are neuroticism (Abdullah et al., 2016; Gupta, 2008). Thus the researchers defined personality traits as distinctive attributes that have the capacity to guide human behavior.

\subsection{Flexible wellbeing, organizational creativity and personality traits}

Empirically, limited studies exist that combines the three constructs (flexible wellbeing, organizational creativity, personality traits) and most of the results have been inconclusive. For instance, Sun et al. (2017) found that a link existed between personality traits and wellbeing, but the precise correlates vary across wellbeing dimensions and within each Big Five domain. Also, Chau et al. (2018) postulated that educators' creative personality has a significant positive effect on individual innovation behavior. In addition, creative personality has a positive effect on wellbeing; as well as, mediated the effect of wellbeing between educators' creative personality and innovation behavior. Likewise, Zhou and Shalley (2018) and Umukoro et al. (2021) found that individual characteristics, work environment, organizational context, and contextual factors either boost or restrict creativity. Meanwhile, a study by Su et al. (2018) hypothesized that while personality traits and originality are associated; personality trait of openness to experience is highly correlated with novelty.

A work by Chau et al. (2018) supported previous findings that creative personality is linked with openness to experience and the working environment of a university influences creative personality of faculty, creativity-related productivity, and performance. In line with these findings, two persons exposed to a similar situation could have dissimilar responses due to internal and external factors such as personality, age, gender, and people's past experiences, and atmosphere.

Additional studies revealed that while conscientious workers were found to be more empowered, extraverts were capable of handling their work-related tasks and competencies as service workers (Yazdi \& Mustamil, 2015). Supporting Yazdi and Mustami (2015) submission, Sun et al. (2017) found that extraverted and non-neurotic individuals experienced higher wellbeing but, the degree of the experience is imprecise and incomplete since individuals respond differently to the dimensions of wellbeing. Summarily, Baer and Oldham (2006) proposed that there could be a link between organizational creativity, personal and contextual factors to increase creativity.

\subsection{Theory}

The core of this paper is underpinned on the Person-Environment (P-E) Fit Theory propounded by Kaplan (1950) and revised in 1974 by French et al. The assumption is that, the degree/level to which a person and environmental characteristics match, are related, and is integrated stimuluses creativity and performance. Also, the P-E fit research focuses explicitly on the match or congruence between individuals and their environments as a key determinant of wellbeing, effectiveness, and creativity (Zhou \& Shalley, 2018). Consequently, demanding work conditions could have a negative impact on flexible wellbeing, but this effect can be mitigated through increased levels of job control and operational resources (Blomberg et al., 2017; van Vianen, 2018).

\section{Methodology}

The study adopted a cross-sectional survey research design. Applying this research design is in consonance with the works of Chau et al. (2018) in a study on creative personality and innovation behavior-wellbeing as the mediator and, Puryear et al. (2017) on relating personality and creativity: considering what and how we measure. Thus, in order to place emphasis on evidences and obtain data about individuals at a particular time on people's principles, motivations, and behavioral patterns justified the application of the cross-sectional research design (Zikmund et al., 2012). Southwest Nigeria was used as the geographical location in this paper. This is because 46 percent (36 private universities) of the total number of private universities in Nigeria officially operates in Southwest Nigeria (NUC, 2019).

More so, eight (8) from the thirty-six (36) private universities were selected grounded on the following criteria, (1) year of university accreditation which was within the first 10 years (1999 to 2009) of licensing private universities in Nigeria; since these private universities have survived 
the formative phases of university establishment; (2) ownership of the university (individual, faith-based, partnership); and (3) ranking on Joint Admissions Matriculation Board (JAMB) 2017 data, based on, popularity, academic stability, affordability, quality of academic staff and available facilities in defining candidates' preferred choice of universities (Economic Confidential, 2017). The private universities selected were, Covenant University (1st) and Babcock University (2nd) in Ogun State, Bowen University (4th), and Redeemer's University (21st) in Osun State. Afe Babalola University (3rd) in Ekiti State, Caleb University (23rd) in Lagos State, Lead City University (22nd) in Oyo State, and Achievers University (30th) in Ondo State, Nigeria. Full-time academic staff ranked from Senior Lecturer to Professor constituted the target population. Krejcie and Morgan (1970) formula $\left[X^{2} N P \times(1-P) / d^{2}(N-1)+X^{2} P\right.$ $(1-P)]$ for sample determination was used to obtain a sample size of six hundred and twenty-one (621):

$$
S=\frac{X^{2} N P \times(1-P)}{d^{2}(N-1)+X^{2} P(1-P)} .
$$

Selected private universities with target population of 2.376 academic staff:

$$
\begin{aligned}
& S=\frac{(1.96)^{2} \times 2376 \times 0.5(1-0.5)}{(0.04)^{2} \times(2376-1)+(1.96)^{2} \times 0.5(1-0.5)} ; \\
& S=\frac{(3.8316) \times 2376 \times 0.5(0.5)}{(0.0016) \times(2375)+(3.8316) \times 0.5(0.5)} ; \\
& S=\frac{9103.9 \times 0.25}{3.8+0.9579} ; \\
& S=\frac{2275.975}{4.7579}
\end{aligned}
$$

$S=478+143(30 \%$ of the sample added to reduce the number of unreturned data to either reduce missing data or take care of non-response occurrence (Zikmund et al., 2012) $=\mathbf{6 2 1}$.

To ensure representativeness, generalization of study result, and to capture key population characteristics in the study sample, for ease, accuracy of representation, and reduction in statistical estimation of error and bias (Gorondutse \& John, 2018), the study adopted the proportionate and multi-stage stratified sampling techniques in accordance with established selection criteria. A structured questionnaire (Carson et al., 2005; Dul \& Ceylan, 2011; Junior Cycle Wellbeing Guidelines, 2017; Kinman \& Wray, 2019; Shimomitsu et al., 2000) was validated and used for the study. The questionnaire items were adopted and adapted from reviewed literature since the question items had already been applied in conducting similar studies in other climes and sectors.

Using $10 \%$ of the sample size, a pilot test was carried out on the questionnaire along with validity and reliability test. While to ensure reliability of the study instrument according to Griffee (2012), the content, criterion, and construct validity were established. The following results were obtained for adapted instruments applied in earlier works that has been analytically studied and authenticated: (Organizational creativity $(\alpha)=$ 0.86 , Flexible Wellbeing $(\alpha)=0.97$, Personality Traits $(\alpha)=0.85$ (Amabile \& Pratt, 2016; McCrae, 1987). The reliability test yielded Cronbach's Alpha coefficients from 0.856 to 0.863 from the internal consistency test for the constructs. Thus, the research questionnaire was considered reliable since the Cronbach's alpha was greater than (>) 0.70 (Livingston, 2018). The response rate was $85.7 \%$ (532) based on copies of questionnaire retrieved from participants and established suitable for this study after conducting data treatment (missing data, outliers, normality test such as, skewness and kurtosis, homoscedasticity test by applying the Bartlett test of Sphericity and multi-collinearity test by applying the variance inflation factor [VIF]). The Statistical Package for Service Solutions SPSS 21.0 using an SPSS add-on called process analysis was used to analyze the data. The mathematical model designed based on the research objective is presented below:

$$
Y=f(X),
$$

where: $Y=$ Organizational Creativity (ORGCRE); $X=$ Flexible Wellbeing (FWB); $Z$ = Personality Traits (PET).

The functional relationship is:

$$
\begin{aligned}
& \text { ORGCRE }=\beta_{0}+\beta_{1} F W B_{i}+\beta_{2} P E T_{i}+ \\
& \beta_{3} F W B \times P E T_{i}+\mu_{i},
\end{aligned}
$$

where: $\beta_{0}=$ Constant term; $\beta_{1}=$ Coefficient of flexible wellbeing; $\beta_{2}=$ Coefficient of personality traits; $\beta_{3}$ $=$ Coefficient of Interaction of flexible wellbeing and personality traits; $\mu=$ Error term (Stochastic variable).

ORGCRE $=\beta_{0}+\beta_{1} F W B_{i}+\mathrm{z}_{1 \mathrm{a}} O P E_{i}+\mathrm{z}_{1 \mathrm{~b}} C O_{i}+$ $\mathrm{z}_{1 \mathrm{c}} E X_{i}+\mathrm{z}_{1 \mathrm{~d}} A G_{i}+\mathrm{z}_{1 \mathrm{e}} N E_{i}+\beta_{1} \mathrm{z}_{1} F W B \times P E T_{i}+\mu_{i}$,

where: $\beta_{0}=$ Constant term; $\beta_{1}=$ Coefficient of flexible wellbeing; $\mathrm{z}_{1 \mathrm{a}}=$ Coefficient of openness to experience; $\mathrm{z}_{1 \mathrm{~b}}=$ Coefficient of conscientiousness; $\mathrm{z}_{1 \mathrm{c}}=$ Coefficient of extraversion; $z_{1 d}=$ Coefficient of agreeableness; $z_{1 \mathrm{e}}$ $=$ Coefficient of neuroticism; $\beta_{1} z_{1}=$ Coefficient of Interaction of flexible wellbeing and personality traits; $\mu$ $=$ Error term (Stochastic variable).

The hypothesis was tested at $95 \%$ confidence interval using moderated (hierarchical) multiple regression analysis. The study apriori expectation result is that a positive and significant effect will be observed between flexible wellbeing, organizational creativity and personality traits. More so, the study adhered strictly to ethics of research which included anonymity and confidentiality during the data gathering process, and participants had the right to discontinue participating in the study after they have started. Also, the works of other scholars were duly acknowledge. 


\section{Results}

The formulated hypothesis was tested by applying a hierarchical multiple regression analysis using SPSS add-on called process analysis was implemented as presented in Tables 1-4.

The purpose of the hypothesis was to examine the moderating effect of personality traits (openness to experience, conscientiousness, extraversion, agreeableness, neuroticism) on the relationship between flexible wellbeing and organizational creativity.

The introduction of the moderator (personality traits) in Table 1 significantly improved the effect of personality traits on the relationship between flexible wellbeing and organizational creativity $\left(\Delta R^{2}=0.470, p<0.05\right)$. Thus flexible wellbeing and personality traits explained $47 \%$ of the variation in organizational creativity. Furthermore, the $F$ value in Table 1 was statistically significant $(\Delta F(3.528)=$ $155.835, p=0.000)$ and revealed that the influence of the independent variable and the moderator were significant in the model.
Results of the analysis in Table 2 showed a statistically significant coefficient result for flexible wellbeing $(\beta=0.594, t=14.790, p<0.05)$. Indicating that, there is a linear dependence of organizational creativity on flexible wellbeing. This result implied that for every unit increase in flexible wellbeing, organizational creativity increased by 0.594 units.

Furthermore, personality traits $(\beta=0.279, t=6.039$, $p<0.05)$ was statistically significant. The result indicated that personality traits had a positive and significant effect on organizational creativity. This showed that for every unit increase in personality traits, organizational creativity increased by 0.279 units.

Introduction of the interaction term (flexible wellbeing $\times$ personality traits) revealed a negative and significant effect $(\beta=-0.285, t=-3.685, p=0.003$ at $p<0.05)$. Likewise, when interaction term, flexible wellbeing $\times$ personality traits, was introduced, the beta coefficient was -0.285 meaning that for every unit change in interaction term, organizational creativity would decrease by 0.285 units.

Table 1. Model summary of regression analysis for moderating effect of personality traits between flexible wellbeing and organizational creativity (source: Field Survey, 2019)

\begin{tabular}{|c|c|c|c|c|c|c|}
\hline$R$ & $R-s q$ & $M S E$ & $F$ & $d f 1$ & $d f 2$ & $P$ \\
\hline 0.685 & 0.470 & 0.143 & 155.835 & 3 & 528 & 0.000 \\
\hline
\end{tabular}

Table 2. Model of regression analysis (source: Field Survey, 2019)

\begin{tabular}{|l|c|c|c|c|c|c|}
\hline \multicolumn{1}{|c|}{ Model } & Beta & Se & $T$ & $P$ & LLCI & ULCI \\
\hline Constant & 4.661 & 0.018 & 259.420 & 0.000 & 4.625 & 4.696 \\
\hline Flexible Wellbeing & 0.594 & 0.040 & 14.790 & 0.000 & 0.515 & 0.673 \\
\hline Personality Traits & 0.279 & 0.046 & 6.039 & 0.000 & 0.189 & 0.370 \\
\hline Flexible Wellbeing $\times$ Personality Traits & -0.285 & 0.077 & -3.685 & 0.003 & -0.437 & -0.133 \\
\hline Outcome Variable: Organizational Creativity
\end{tabular}

Table 3. Indirect effect(s) of X on Y (source: Field Survey, 2019)

\begin{tabular}{|c|c|c|c|c|c|}
\hline & $\Delta R^{2}$ & $F$ & $d f 1$ & $d f 2$ & $P$ \\
\hline$X \times W$ & 0.014 & 13.579 & 1 & 528 & 0.003 \\
\hline
\end{tabular}

Table 4. Model of regression analysis of individual personality traits (source: Field Survey, 2019)

\begin{tabular}{|l|c|c|c|c|c|c|}
\hline \multicolumn{1}{|c|}{ Model } & Beta & Se & $T$ & P & Partial & Part \\
\hline (Constant) & 4.661 & 0.018 & 259.420 & 0.000 & 4.625 & 4.696 \\
\hline Openness to experience (OPE) & 0.400 & 0.072 & 5.543 & 0.000 & 0.235 & 0.169 \\
\hline Conscientiousness (CO) & 0.270 & 0.073 & 3.695 & 0.000 & 0.159 & 0.113 \\
\hline Extraversion (EX) & 0.195 & 0.076 & 2.565 & 0.011 & 0.111 & 0.078 \\
\hline Agreeableness (AG) & 0.201 & 0.071 & 2.839 & 0.005 & 0.123 & 0.087 \\
\hline Neuroticism (NE) & 0.214 & 0.074 & 2.900 & 0.004 & 0.126 & 0.088 \\
\hline Flexible Wellbeing & 0.594 & 0.040 & 14.790 & 0.000 & 0.515 & 0.673 \\
\hline Flexible Wellbeing $\times$ Personality traits & -0.285 & 0.077 & -3.685 & 0.003 & -0.437 & -0.133 \\
\hline Dependent variable: Organizational Creativity & & & & \\
\hline
\end{tabular}


Result revealed that personality traits had a negative and statistically significant moderating effect on the relationship between flexible wellbeing and organizational creativity.

Also, the $\Delta R^{2}$ in Table 3 as a result of the introduction of the interaction term was 0.014 at $p=0.003(p<0.05)$ which indicated that the interaction term (flexible wellbeing $\times$ personality traits) accounted for additional 1.4\% variation in organizational creativity and was statistically significant. This means that the introduction of the moderator (personality traits) significantly increased the model on the effect of personality traits on the relationship between flexible wellbeing and organizational creativity by 0.014 .

The established regression equation from the results is stated as follows:

$$
\begin{aligned}
& \text { ORGCRE }=4.661+0.594 F W B+0.279 P E T- \\
& 0.285 F W B \times P E T,
\end{aligned}
$$

where: ORGCRE = Organizational Creativity; $F W B=$ Flexible Wellbeing; PET $=$ Personality Traits; $F W B \times$ $P E T=$ Interaction of Flexible Wellbeing and Personality Traits.

Further, results in the coefficient Table 4 and Figure 1 showed the $\beta$ coefficients for the constant and five predictors of personality trait were as follows; Constant $(\beta=$ $4.661, t=-259.420, p=0.000)$ was significant; Openness to experience (OPE), $(\beta=0.400, t=5.543, p=0.000)$ was significant; Conscientiousness (CO), $(\beta=0.270, t=3.695$, $p=0.000)$ was significant; Extraversion (EX), $(\beta=0.195$, $t=2.565, p=0.011$ ) was significant; Agreeableness (AG), $(\beta=0.201, t=2.839, p=0.005)$ was significant, Neuroticism (NE), $(\beta=0.214, t=2.900, p=0.004)$ was significant, and Flexible Wellbeing $(\beta=0.594, t=14.790, p=0.000)$ was significant. While Flexible Wellbeing $\times$ Personality traits $(\beta=-0.285, t=-3.685, p=0.003)$ was negative but significant.

Based on the results from the analysis, the best fitting model for predicting organizational creativity would be the linear individual results of OCEAN and flexible wellbeing. Also, from the five personality traits, openness to experience had the most significant result $(\beta=0.400, p=0.000)$ on the relationship between flexible wellbeing and organizational creativity. Although, the interaction of Flexible Wellbeing $\times$ Personality traits was significant, it had negative correlation with organizational creativity.
Thus, the model is:

ORGCRE $=4.661+0.594 F W B+0.400 O P E+0.270 C O+$ $0.195 E X+0.201 A G+0.214 N E-0.285 F W B \times P E T$.

The model result implied that statistically from the regression result, the aggregated result was significant for the Model, and the individual results showed that personality traits moderating variables had statistically significant effect on the relationship between flexible wellbeing and organizational creativity. The analysis also showed that based on the coefficient (parameter estimate) results, while increase in flexible wellbeing and personality traits would increase organizational creativity by $1.542,0.400$, $0.270,0.195,0.201$, and 0.214 units respectively, for every unit change in interaction term (flexible wellbeing $\times$ personality traits), organizational creativity would decrease by 0.285 units.

The result of the analysis indicated that although the interaction or collaboration of flexible wellbeing measures and personality traits in order to achieve and sustain organizational creativity should be encouraged, thoughtfulness should be maintained in the implementation of this strategy as the interaction may not always yield positive creative results. This could either be due to the demographic spread of the participants and or the intrinsic and extrinsic factors motivating workers to be creative. More so, the results could imply that, deposited in academics is an element of creativity notwithstanding their personality traits, but to enhance creativity, attention should be given to the introduction of flexible wellbeing measures since individuals respond differently.

\section{Discussion of findings}

The interaction term result revealed personality traits had a significant moderating effect on the relationship between flexible wellbeing and organizational creativity; although the effect was negative. Conceptually, this result is consistent with previous scholars' comments from different sectors, that employee creativity and wellbeing are important for organizational creativity. As such, there is a link between employees' demonstration of creativity at work, and production of novel and useful ideas about organizational products, practices, publications, services, or procedures.

Therefore, the role personality traits play has received considerable attention in the creativity and wellbeing literature (Qinxuan et al., 2013; Puryear et al., 2017). However,

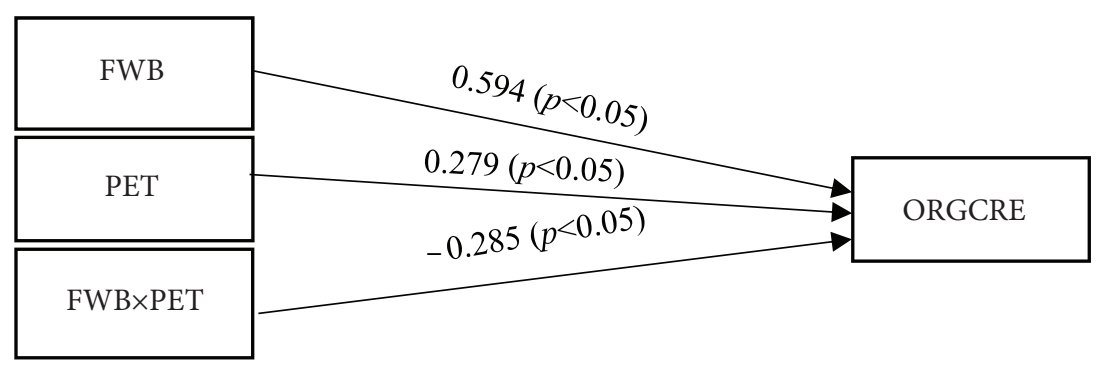

Figure 1. Regression model 
Abdullah et al. (2016) maintained that based on personality traits and the intricacies among the BIG Five traits, the integration with the concept of creativity and wellbeing is more complex than initially perceived. In line with previous comments, Sun et al. (2017) found that personality traits are associated with wellbeing and creativity, but the precise strength and direction of the correlates vary across wellbeing dimensions and within each Big Five domain. Likewise, other researchers opined that individual characteristics, work environment, and other contextual factors either supports or hamper workers creativity (Gorondutse \& John, 2018; Zhou \& Shalley, 2018).

Further empirical evidence revealed that situating the study findings in previous works conducted in academia, scholars found that to practice creativity in daily routine, there should be an interaction between personality, creative intentions, the workload, contextual factors, and wellbeing measures; because the workload and contextual factors have a significant effect on creativity among educators (Alghamdi et al., 2017; Gorondutse \& John, 2018). An earlier study by Baer and Oldham (2006) and Amabile and Pratt (2016) postulated that there is a link between personal and contextual factors to increase organizational creativity. Thus, individual differences as a result of personality traits and wellbeing correlate with organizational creative achievement at work.

Correspondingly, Zhou and Shalley (2018) postulated that although, the combined result of personality traits is significant on wellbeing, contextual factors, and creativity; employees and teams exhibit high levels of creativity in and for an organization when wellbeing and operational resources continuously fit. Also, the effect of certain individual characteristics on creativity differs contingent on differences in the context in which the individual is embedded. Hence, how the Big 5 dimensions of personality interact with characteristics of the work environment to predict creativity and creative outcomes is germane (Montag et al., 2012; Zhou \& Shalley, 2018). So, although wellbeing measures are significantly related to personality traits, the personality traits of each individual to a large extent determine the interaction between the environment in the workplace, wellbeing, and outcomes in terms of organizational creativity.

Further, the results for the individual model in Table 4 revealed that all the individual personality traits [OCEAN] had a significant positive effect on the relationship between flexible wellbeing and organizational creativity. Although, the level of effect as shown by the beta coefficient values indicated that, academics with traits of openness to experience and conscientiousness had a higher effect with moderating the relationship between wellbeing and organizational creativity. These results are consistent with findings from previous works (Ali, 2018; Chau et al., 2018; Chen et al., 2017). More so, while other researchers agreed that there is an association between personality traits, wellbeing, and organizational creativity, most of these studies were inconclusive with results on the individual personality traits effect (Ali, 2018; Gorondutse \& John,
2018; Puryear et al., 2017; Yazdi \& Mustamil, 2015; Zhou \& Shalley, 2018).

The inconclusive results could be related to the organizational creativity discourse (Blomberg et al., 2017), the work environment foci (Bakker \& Demerouti, 2014), demographic age group of employees (Deloitte Global, 2018, 2019), and or job demands and resources (Bakker, 2015). Nonetheless, according to Visagie (2010), despite the position that employees behave differently as a result of varied individual and or combined personality traits, the essence to an organization is to ensure that workers behaviour is channelled towards being advantageous and productive to the worker and organization.

Further, although the interaction of flexible wellbeing and personality traits in this study was significant, it had a negative effect on organizational creativity. This could imply that every worker has creative potential despite their personality traits as long as wellbeing measures align with an organizational creative drive. It could also be related to the submission of Klijn and Tomic (2010) that employers who select employees for creative behaviour based on perceived personality traits without wellbeing measures have not had much success.

Theoretically, the findings are in consonance with P-E fit research that there is a match or congruence between individuals and their environments as a key determinant of wellbeing, effectiveness, and creativity (Zhou \& Shalley, 2018). Therefore, demanding conditions at work could have a negative impact on flexible wellbeing, but this effect can be mitigated through increased levels of job control and operational resources (Blomberg et al., 2017). Consequently, the interactionist model of creativity and P-E fit theory supports the position that the personality of an individual influences the relation between the work environment wellbeing measures and creativity either positively or negatively.

The researchers concluded that statistically, personality traits significantly moderated the effect between the relationship of flexible wellbeing and organizational creativity. Also, though the individual personality traits had a positive and significant effect on this study, it could exhibit varied effects for other workers due to different dynamic individual characteristics, the work environment, and operational resources available for creativity. Hence, while the support for the interaction between flexible wellbeing and personality traits to achieve and sustain organizational creativity for competitive advantage in higher education is relevant, fitting and refined measures should be the maxim in the application of this strategy.

\section{Conclusions and recommendations}

On the strength of the findings in this paper, personality traits had a significant moderating effect on the relationship between flexible wellbeing and organizational creativity in selected private universities in South-West Nigeria. However, the direction of the effect was negative. In summary, every worker has creative potential despite their 
personality traits as long as wellbeing measures align with an organizational-creative drive.

Also, personality traits developed in individuals based on several psychological systems define an individual's unique adjustments to the environment for creative output levels. Thus, personality endures and predicts people's characteristics concerning emotions, motivations, interpersonal interactions, and attitudes which differ from their abilities but are transient and finite. In light of the conclusions, wellbeing measures and operational resources should continuously fit workers-creative job demands and progressively respond to the changing education environment and other businesses. Accordingly, management should critically investigate if the current operational policies in their institution support the above scenarios.

Therefore, this study contributes to the body of knowledge on management eagerness to improve creativity levels through the implementation of flexible wellbeing measures to expand academic staff intellectual capacity, produce novel ideas, and provide solutions to issues for national and international institutional recognition. Therefore, it is recommended for management to tailor wellbeing policies and practices to organizational and workers-creative drive. Additionally, management should ensure that wellbeing measures are redefined progressively and fine-tuned since there is no one-size-fits-all approach to designing an effective wellbeing strategy due to the unique complexities in individual personality traits. As such, the flexible wellbeing content should respond to the organizational creativity needs, characteristics, and those of its dynamic and complex employees.

\section{Limitations and future research}

Future studies should apply longitudinal research design and extend the concept of personality traits and organizational creativity by expanding the scope to public universities and other sectors to broaden the insight on flexible wellbeing.

\section{References}

Abdullah, I., Omar, R. B., \& Panatik, S. A. (2016). A literature review on personality, wellbeing, creativity and innovative behavior. International Review of Management and Marketing, 6(1), 177-182.

Abubakar, A., Hilman, H., \& Kaliappen, N. (2018). New tools for measuring global academic performance. SAGE Open, 1-10. https://doi.org/10.1177/2158244018790787

Alghamdi, N., Aslam, M., \& Khan, K. (2017). Personality traits as predictor of emotional intelligence among the university teachers as advisors. Education Research International, 1-6. https://doi.org/10.1155/2017/9282565

Ali, I. (2018). Personality traits, individual innovativeness and satisfaction with life. Journal of Innovation and Knowledge, 4(1), 38-46. https://doi.org/10.1016/j.jik.2017.11.002

Amabile, T. A., \& Pratt, M. G. (2016). The dynamic componential model of creativity and innovation in organizations: Making progress, making meaning. Research in Organizational Behavior, 36(1), 157-183. https://doi.org/10.1002/jocb.001
Baer, M., \& Oldham, G. R. (2006). The curvilinear relation between experienced creative time pressure and creativity: Moderating effects of openness to experience and support for creativity. Journal of Applied Psychology, 91(1), 963-970. https://doi.org/10.1037/0021-9010.91.4.963

Bakker, A. B. (2015). A job demands-resources approach to public service motivation. Public Administration Review, 75(5), 723-732. https://doi.org/10.1111/puar.12388

Bakker, A. B., \& Demerouti, E. (2014). Job demands-resources theory. In C. Cooper \& P. Chen (Eds.), Wellbeing. A complete reference guide (pp. 37-64). Wiley-Blackwell.

https://doi.org/10.1002/9781118539415.wbwell019

Blomberg, A., Kallio, T., \& Pohjanpää, H. (2017). Antecedents of organizational creativity: Drivers, barriers or both? Journal of Innovation Management, 5(1), 78-104. https://doi.org/10.24840/2183-0606_005.001_0007

Carson, S. H., Peterson, J. B., \& Higgins, D. M. (2005). Reliability, validity, and factor structure of the creative achievement questionnaire. Creativity Research Journal, 17(1), 37-50. https://doi.org/10.1207/s15326934crj1701_4

Cervone, D., \& Vittorio, C, G. (2000). Personality: Determinants, dynamics, and potentials. England, Cambridge University Press.

Chartered Institute of Personnel and Development. (2019). Health and wellbeing at work. https://www.cipd.co.uk/about/ who-we-are/annual-report

Chau, K. Y., Zhu, Y. L., Shen, H. W., \& Huang, S. Z. (2018). A study on creative personality and innovation behavior-wellbeing as the mediator. Journal of Interdisciplinary Mathematics, 21(2), 253-264. https://doi.org/10.1080/09720502.2017.1420556

Chen, P. S., Huang, C. Y., Yu, C. C., \& Hung, C. C. (2017). The examination of key performance indicators of warehouse operation systems based on detailed case studies. Journal of Information and Optimization Sciences, 38(2), 367-389. https://doi.org/10.1080/02522667.2016.1224465

Corazza, G. (2016). Potential originality and effectiveness: The dynamic definition of creativity. Creativity Research Journal, 28(3), 258-267. https://doi.org/10.1080/10400419.2016.1195627

Cornell University, INSEAD, \& WIPO. (2015). The Global innovation index 2015: Effective innovation policies for development. World Intellectual Property Organization.

Deloitte Global. (2018). Millennials disappointed in business, unprepared for Industry 4.0. https://www2.deloitte.com/.../ About-Deloitte/gx-2018-millennial-survey-report.pdf

Deloitte Global. (2019). Societal discord and technological transformation create a "generation disrupted". https://www2.deloitte.com/content/dam/Deloitte/global/Documents/AboutDeloitte/deloitte-2019-millennial-survey.pdf

Derecskei, A. (2015). Organizational creativity: The components of organizational creativity in Hungary [Doctoral dissertation, University of Szeged Faculty of Economics and Business Administration, Hungary].

Diener, E., Lucas, R. E., \& Oishi, S. (2018). Advances and open questions in the science of subjective wellbeing. Collabra: Psychology, 4(1), 1-15. https://doi.org/10.1525/collabra.115

Dimnwobi, K. S., Ekesiobi, S. C., \& Mgbemena, M. E. (2016). Creativity, innovation and competitiveness in Nigeria: An economic exploration. International Journal of Academic Research in Economics and Management Sciences, 5(3), 29-52. https://doi.org/10.6007/IJAREMS/v5-i3/2242 
Dul, J., \& Ceylan, C. (2011). Work environments for employee creativity. Applied Ergonomics, 54(1), 12-20.

https://doi.org/10.1080/00140139.2010.542833

Economic Confidential. (2017). Universities rankings - 2017. http://www.Economicconfidential.com

Eyong, E. I., David, B. E., \& Umoh, A. J. (2014). The influence of personality trait on the academic performance of secondary school students in Cross River State, Nigeria. Journal of $\mathrm{Hu}$ manities and Social Science (IOSR-JHSS), 19(3), 12-19. https://doi.org/10.9790/0837-19311219

French, J. R. P., Jr., Rodgers, W. L., \& Cobb, S. (1974). Adjustment as person-environment fit. In G. Coelho, D. Hamburg, \& J. Adams (Eds.), Coping and adaptation (pp. 316-333). Basic Books.

Gorondutse, A. H., \& John, J. A. (2018). The effect of workload pressure on creativity in private higher education institutions (PHEIs). SAGE. https://doi.org/10.9756/IAJBM/V5I1/1810015

Griffee, D. T. (2012). An introduction to second language research methods: Design and data (1st ed.). TESL-EJ Publications.

Gupta, B. (2008). Role of personality in knowledge sharing and knowledge acquisition behaviour. Journal of the Indian Academy of Applied Psychology, 34(1), 143-149.

Gupta, R., \& Banerjee, P. (2016). Antecedents of organizational creativity: A multi-level approach. Verslas Teorija ir Praktika, 17(2), 167-177. https://doi.org/10.3846/btp.2016.624

Ishola, A. A. (2017). Workplace safety management as correlates of wellbeing among factory workers in Oluyole industrial estate, Ibadan, Oyo State Nigeria. African Journal of Social Work, 7(2), 45-51.

Jain, R., \& Jain, C. (2017). Employee creativity: A conceptual framework. Indian Journal of Industrial Relations, 52(3), 484-498.

Junior Cycle Wellbeing Guidelines. (2017). Wellbeing, assessment and reporting. https://ncca.ie/media/2487/wellbeingguidelines_forjunior_cycle.pdf

Kaplan, J. D. (1950). Dialogues of Plato. Washington Square Press. Kinman, G., \& Wray, S. (2019). Wellbeing in academic employees - a benchmarking approach. In Handbook of research on stress and wellbeing in the public sector. Edward Elgar Publishing Limited. https://doi.org/10.4337/9781788970358.00019

Klijn, M., \& Tomic, W. (2010). A review of creativity within organizations from a psychological perspective. Journal of Management Development, 29(4), 322-343. https://doi.org/10.1108/02621711011039141

Krejcie, R. V., \& Morgan, D. W. (1970). Determining sample size for research activities. Educational and Psychological Measurement, 30(3), 607-610.

https://doi.org/10.1177/001316447003000308

Livingston, S. A. (2018). Test reliability - basic concepts. Educational Testing Service.

Lovell, A., \& Beckstrand, G. (2015). The impact of excellent employee wellbeing. O.C. Tanner Institute Global Health and Wellbeing Survey Report.

McCrae, R. R. (1987). Creativity, divergent thinking, and openness to experience. Journal of Personality and Social Psychology, 52(6), 1258-1265.

https://doi.org/10.1037/0022-3514.52.6.1258

Montag, T., Maertz, C. P., \& Baer, M. (2012). A critical analysis of the workplace creativity criterion space. Journal of Management, 38(4), 1362-1386.

https://doi.org/10.1177/0149206312441835

Mudrak, J., Zabrodska, K., Kveton, P., Jelinek, M., Blatny, M., Solcova, I., \& Machovcova, K. (2017). Occupational wellbeing among university faculty: A job demands-resources model. Research in Higher Education, 59(3), 325-348. https://doi.org/10.1007/s11162-017-9467-x

Ndubuisi-Okolo, P. U., Attah, E. Y., \& Anigbogu, T. (2017). Influencing employees job attitude in Nigeria: A critical review. Journal of Business and Management (IOSR-JBM), 19(12), $35-40$.

Nangoy, R., Mursitama, T., Setiadi, N. \& Pradipto, Y. (2020). Creating sustainable performance in the fourth industrial revolution era: The effect of employee's work wellbeing on job performance. Management Science Letters, 10(5), 1037-1042. https://doi.org/10.5267/j.msl.2019.11.006

National Universities Commission [NUC]. (2019). List of universities in Nigeria. https://www.nuc.edu.ng

Odigiri, M., Watson, D., Hayes, C., \& Tekelas, F. (2020). Factors affecting academic job performance in Nigerian Universities; A case study of Delta State University \& Igbinedion University Okada. The Market: International Journal of Business, 1(1), 42-56.

Omole, D. (2018, August 26). Excess workload killing lecturers, ASUU cries out. In P.M. News. https://www.pmnewsnigeria. com/2018/08/26/excess-workload-killing-lecturers-asuucries-out

Organization for Economic Cooperation and Development [OECD]. (2018). Education at a glance 2018. OECD indicators. OECD Publishing. Paris.

https://doi.org/10.1787/eag-2018-en

Osita-Ejikeme, U. E., \& Worlu, G. O. (2017). Personality traits and employee commitment in manufacturing firms in Port Harcourt, Rivers State. International Journal of Advanced Academic Research, Social \& Management Sciences, 3(5), 22-42.

Puryear, J. S., Kettler, T., \& Rinn, A. N. (2017). Relating personality and creativity: Considering what and how we measure. The Journal of Creative Behavior, 70(101), 1-14.

https://doi.org/10.1002/jocb.17

Qinxuan, G., Mingchuan, Y., \& Yu, G. (2013). Linking personality traits and job satisfaction to creativity. Journal of Applied Psychology, 87(3), 482-487.

https://doi.org/10.2991/icacsei.2013.118

Robert, L., Kahn, F., \& Thomas, J. (2020). Well-being: Concepts and measures. Journal of social Issues, 58(4), 627-644. https:// doi.org/10.1111/1540-4560.00281

Rothmann, S., \& Coetzer, E. P. (2003). The big five personality dimensions and job performance. SA Journal of Industrial Psychology, 29(1), 68-74.

https://doi.org/10.4102/sajip.v29i1.88

Sadi, M. (2019). Barriers to organizational creativity: A perspective of national and expatriate academics in Saudi Arabia. Journal of Management Development, 27(6), 574-599. https://doi.org/10.1108/02621710810877839

Shimomitsu, T., Haratani, T., \& Nakamura, K. (2000). The final development of the Brief Job Stress Questionnaire mainly used for assessment of the individuals (pp. 126-164). The Ministry of Labor sponsored grant for the prevention of work-related illness.

Shin, J. C., \& Jung, J. (2014). Academics job satisfaction and job stress across countries in the changing academic environments. Higher Education 67, 603-620.

https://doi.org/10.1007/s10734-013-9668-y

Su, M. H., Wu, C.-H., Huang, K. Y., Hong, Q. B., \& Wang, H. M. (2018). Personality trait perception from speech signals using multiresolution analysis and convolutional neural networks. In Proceedings from 9th Asia-Pacific Signal and Information Processing Association Annual Summit and Conference. APSIPA ASC. https://doi.org/10.1109/APSIPA.2017.8282287 
Sun, J., Kaufman, S. B., \& Smillie, L. D. (2017). Unique associations between big Five personality aspects and multiple dimensions of wellbeing and creativity. Journal of Personality, 86(2), 158-172. https://doi.org/10.1111/jopy.12301

Taylor, T. E. (2015). The markers of wellbeing: A basis for a theory-neutral approach to wellbeing". International Journal of Wellbeing, 5(2), 75-90. https://doi.org/10.5502/ijw.v5i2.5

Umukoro, J. E., \& Egwakhe, A. J. (2019). Flexible wellbeing and smart-head. International Journal of Research Science \& Management, 6(12), 103-118.

Umukoro, J. E., Egwakhe, J. A, \& Falana, R. B. (2021). Rethinking well-being input for creative person. Journal of Business and Entrepreneurship, 9(2), 38-51.

van Vianen, A. (2018). Person-environment fit: A review of its basic tenets. Annual Review of Organizational Psychology and Organizational Behavior, 5, 75-101. https://doi.org/10.1146/annurev-orgpsych-032117-104702

Visagie, C. M. (2010). The relationship between employee attitudes towards planned organizational change and organizational commitment: an investigation of a selected case within the South African telecommunications industry [Doctoral dissertation, Cape Peninsula University of Technology].
World Economic Forum. (2018). The Global Competitiveness Report. The framework of the Global Competitiveness and Risks. http://reports.weforum.org/global-competitiveness-report-2018/

World Economic Forum. (2019). The Global Competitiveness Report. Globalization 4.0: Shaping a New Architecture in the Age of the Fourth Industrial Revolution. https://www. reports. weforum.org/global-competitiveness-report-2019

World Health Organization. (2014). Preventing suicide: A Global imperative. https://www.who.int/publications/i/ item/9789241564779

Yazdi, A. M. T., \& Mustamil, N. (2015). Empowerment potential: Big-Five personality traits and psychological empowerment. International Business and Management, 11(3), 62-69.

Zhou, J., \& Shalley, C. E. (2018). Research on employee creativity: A critical review and directions for future research. Journal of General International Medicine, 25(11), 1244-1247.

Zikmund, W. G., Quinlan, C., Babbin, B., Carr, J. C., \& Griffin, M. (2012). Business research methods. South-Western College, California Publisher. 